\title{
The evolution of learned and innate behavior: Contributions from genetics and neurobiology to a theory of behavioral evolution
}

\author{
ANN JANE TIERNEY \\ University of Toronto, Toronto, Ontario, Canada
}

\begin{abstract}
In recent years, ethologists and psychologists have become increasingly interested in the evolution of the ability to learn and in the relationship between innate and learned behavior. However, recent discussions of behavioral evolution have not adequately incorporated contemporary knowledge of nervous system development and structure. Most discussions are based on the following assumptions: (1) That innate behaviors are programmed by specific genes; (2) that learning requires a larger, more flexible nervous system than does innate behavior; and (3) that the ability to learn is phylogenetically more recent than innate behavior. This paper reviews information about nervous system development and the neurobiology of plasticity and learning that questions the validity of these assumptions. It is hypothesized that behavioral flexibility is phylogenetically primitive and that learned behavioral adaptations may commonly precede innate forms of the same behaviors. The role of genetic assimilation in behavioral evolution is discussed.
\end{abstract}

Since the emergence of ethology in the 1930s, biologists have taken a keen interest in the evolutionary aspects of behavior. As a result, an extensive literature now exists describing how species-specific behaviors adapt animals to their environments. More recently, biologists and psychologists have realized that the ability to learn is also an evolutionary adaptation that allows many animals to make short-term adjustments to changing environments. This realization has generated a number of theoretical discussions on the evolutionary relationship between innate behavior, learning, and adaptation (Alcock, 1979; Gould \& Marler, 1984; Johnston, 1982; Mayr, 1974; Plotkin \& Odling-Smee, 1979; Rozin \& Schull, in press). Basically, these discussions have addressed the problem of why natural selection sometimes favors learning, a complex, perhaps costly adaptation, over innate behavior, a simpler and more common form of adaptation.

Although ideas about the evolution of behavior have developed rapidly in recent years, they have not incorporated contemporary knowledge of genes, nervous system development, and the neurophysiology of plasticity and learning. Animal behaviorists still base their theories on traditional, and now obsolete, beliefs about how genes and nervous systems operate. These beliefs, or "conventional wisdom," are outlined in the following section.

The evolution of innate behavior, for example, is intuitively rather easy to understand if one adopts the common assumption that particular innate behaviors are programmed by particular genes. In this view, certain

I am very grateful to B. Tierney, S. J. Shettleworth, B. Johnson, D. van der Kooy, T. D. Johnston, T. J. Roper, and H. C. Plotkin for their many valuable comments on this manuscript.

The author was in the Department of Zoology at the University of Toronto. Her present address is: Boston University Marine Program, Marine Biological Laboratory, Woods Hole, MA 02543. genes construct the discrete neural structures that underlie species-specific behaviors. Such behaviors can be altered by mutations of their genetic blueprint, and as a result behavioral evolution may occur. The evolution of learning, on the other hand, is intuitively problematic. What sorts of genes and how many are required to construct neural circuits that are capable of many behaviors? Such considerations have led some authors to conclude that learning requires a more elaborate genetic base than does innate behavior:

There are things that have to be learned, such as the individual characteristics of a particular mate or the location of a nest site. All elements that can be innate, however, will be innate. Instinct costs less than learned behavior, in the currency of genetic information (Williams, 1966, p. 83).

Johnston (1982) also speculates that learning may be genetically expensive relative to innate behavior. These views contribute to a common belief that learning is in general a more complex and evolutionarily advanced adaptation than is innate behavior.

This paper discusses the biological basis of behavior and learning from two angles. One angle concerns how genes program the development of the nervous system and, in turn, program behaviors. I describe several welldocumented phenomena in nervous system development which illustrate the very indirect relationship that exists between genes and behaviors. Thus, the ideas about behavioral evolution cited above are based on the notion that specific genes directly program behaviors, a notion that, I will argue, is incorrect. The second angle concerns the neurophysiology of learning. I describe several examples of neuronal plasticity which are ubiquitous in nervous systems and which in some cases appear to be important in learning. The implication here is that learning may be a 
very basic property of nervous systems, not an unusual and costly evolutionary adaptation. The final section presents an evolutionary model that differs from traditional ideas, but is consistent with the information presented in this paper. In particular I discuss the possibility, alluded to by Haldane (1959), that learned behaviors may commonly precede innate forms of the same behaviors and that genetic assimilation may play an important role in behavioral evolution.

I assume that no actual dichotomy exists between innate, or " instinctive," behavior and learning, but that they operate together to produce many behaviors. The concept of instinct and the classification of behavior into two distinct categories-instincts and learning-have been repeatedly and justly criticized (Hinde, 1970; Lehrman, 1953) and are no longer used by most ethologists. Current definitions often emphasize the idea that behavior varies continuously from being independent of learning to being highly dependent on learning (Alcock, 1979). Staddon (1983) refers to innate behaviors as "canalized." This term can express the idea that behaviors may be more or less affected by learning. Thus, a behavior may be strongly canalized (i.e., courtship song recognition in brood parasitic cowbirds; King \& West, 1977) or weakly canalized (i.e., the begging response of gull chicks; Hailman, 1967). The term "canalization" is also useful because it avoids the instinct-learning dichotomy connoted by the terms "innate" and "instinctive." I have consequently adopted it in this paper: canalized behaviors are those that are apparently unlearned and which are relatively unamenable to modification by learning. For present purposes, learning may be defined broadly and simply as a modification of behavior that involves the nervous system and that results from practice or a specific experience with an external event.

\section{Conventional Wisdom}

There exists a set of traditional ideas common to biologists and psychologists who study behavior and learning as biological adaptations. Although compelling evidence for these notions has never been available, that they are true is implicit in the writings of many scientists. I will express these ideas explicitly so they may easily be contrasted with the alternative notions presented below. The conventional wisdom goes something like this:

Canalized, stereotyped behaviors are associated with simple nervous systems. Learning requires more neurons and is associated with large complex nervous systems. Therefore, invertebrates show mainly canalized, rigid behaviors, whereas vertebrates, particularly birds and mammals, are capable of flexible learning. Canalized behaviors are genetically programmed and evolve by natural selection in a manner identical to the evolution of morphological characteristics. The ability to learn is phylogenetically more recent than canalized behavior and emerged gradually with the evolution of large, complex brains.
Certain of these traditional notions deserve further comment. First, the idea that invertebrates rely on canalized behavior or on very simple, highly programmed learning is presently being replaced with evidence demonstrating unequivocal association learning in such animals as molluscs (Alkon, 1980; Kandel \& Schwartz, 1982; Sahley, Rudy, \& Gelperin, 1981), blowflies (McGuire \& Hirsch, 1977), and honeybees (Couvillon \& Bitterman, 1980). Learning in birds and mammals, on the other hand, has proven in many cases to be far from completely flexible. Examples of genetic constraints on learning include bird song learning (Marler \& Mundinger, 1971), imprinting (Bateson, 1971), and cue-to-consequence specificity in taste aversion learning (Garcia \& Koelling, 1966). Thus, new concepts of invertebrate and vertebrate learning are rapidly replacing the traditional notions outlined above. However, a related piece of conventional wisdom-that learning requires a larger, more complex CNS than does canalized behavior-persists unchallenged. Recent statements of this "fact" can be found in Mayr (1974, p. 657), Barash (1977, p. 42), Alcock (1979, p. 98), and Johnston (1982, p. 86).

The idea that canalized behaviors are genetically programmed and evolve in the same manner as structural traits was emphasized by the classical ethologists and remains a cornerstone of behavioral biology. Most biologists also believe that the ability to learn is a genetically programmed trait (Alcock, 1979). Whether viewed as a general ability or as a set of specialized abilities (Johnston, 1981; Rozin, 1976), learning is invariably regarded as an "advanced" characteristic, evolved relatively recently from canalized behavior. An explicit illustration of this assumption is shown in Shepherd (1983, p. 546). It is implicit in other evolutionarily oriented discussions of learning. Mayr (1974, p. 652), for instance, comments on how rarely "genetically fixed behavior patterns have been replaced by the capacity for the storage of individual acquired information."

\section{Alternative Hypotheses}

Here I suggest a set of hypotheses that diverge from the traditional ideas outlined above:

Neural plasticity, and consequently learning, is a basic property of all central nervous systems and does not require more neurons or more DNA than strongly canalized behavior. The relationship between genes and behavior is too tenuous and indirect for us to think usefully of genes as programming behaviors. Behavioral evolution may commonly rely on evolutionary processes such as genetic assimilation and consequently occur more rapidly than morphological evolution. Behavioral flexibility is phylogenetically primitive; canalized behaviors may be derived from the plasticity inherent in all nervous systems.

Clearly, I am treating learning as a very general process indeed. This view does not deny the existence of constraints on many kinds of learning, but argues that it was 
the constraints that evolved, not the ability to learn. Also, the statement that learning does not require more neurons than canalized behavior does not imply that complex behavior may not use more neurons than simple behavior. Rather, it states that, in terms of neuron numbers, it doesn't matter whether a given complex behavior is closed or open to modification.

\section{Genes, Neurons, and Behavior}

Implicit in many discussions concerning the genetic control of behavior is the notion that somewhere in the genome there exists a specific segment of DNA (or set of DNA segments) that specifies the neural circuitry responsible for a given behavior. According to Hall and Greenspan $(1979$, p. 129), "the single gene approach to behavioral genetics and neurogenetics starts out with the knowledge that genes blatantly specify the assembly of the nervous system and the components that underlie the function of the cells in that system. Our 'only' questions, then, revolve around trying to find out how specific genes control neurobiological phenomena." Rozin (1976, p. 260) comments, "There are two ways in which [behavior program] $X$ is represented in such an organism: first, as a genetic blueprint and, second, as a set of circuits in the brain."

In this section, I will argue that the idea of genes containing "blueprints" for behaviors is probably false. I will emphasize, instead (as have others; Bateson, 1984; Partridge, 1983; Stent, 1981), the concept of nervous system development as an epigenetic phenomenon in which, once set into motion by the entire genome, one event simply leads to another. A functional nervous system depends on the astonishing ability of developing neurons to select among thousands of candidate targets precisely the correct cell with which to establish a connection. But this precision is best viewed as a developmental consequence of the two cells' being in a particular place at a particular time rather than of genes' specifying the formation of neural circuitry. In this section, I briefly describe three phenomena that illustrate the importance of epigenetic factors in nervous system development. The purpose of these examples is not to suggest that the genotype has no influence on behavior. Rather, they attempt to show that this influence, indubitably important in all species, does not work the way animal behaviorists usually assume.

\section{Epigenetic Phenomena in Nervous System Development}

Isogenic animals. If the development of neural connections is under absolute genetic control, one would expect nervous system structure to be identical in genetically identical animals raised under uniform environmental conditions. This is not the case. Studies of isogenic animals have revealed that although neuron number and gross anatomical structure are constant, significant variability occurs in the number and location of synaptic contacts between cells. For example, in the crustacean Daphnia magna, receptor cells in the eye show differences over distances of several micrometers in shape, location, and branching patterns of nerve fiber terminals (Macagno, Lopresti, \& C. Levinthal, 1973). F. Levinthal, Macagno, and C. Levinthal (1975) have also observed variability in dendritic branching patterns in Mauthner and Muller cells in members of a single clone of the fish Poecilis formosa. Similar findings have been reported in studies of isogenic grasshoppers (Goodman, 1979) and isogenic nematodes (Ward, Thomson, White, \& Brenner, 1975). F. Levinthal et al. $(1975$, p. 327) conclude: "There are factors as yet unknown that control complexity in all or part of the nervous system of an individual animal and which are not associated with any genetic variability between animals."

Abnormal connections. During normal development, nerve cells move in precise and orderly ways to form highly stereotyped patterns of connectivity. However, should normal development be disrupted by injury or environmental or genetic perturbation, neurons show remarkable flexibility in where they send their axons and on what target cells they will synapse (Jacobson, 1978).

The Siamese cat provides an interesting example of a genetic perturbation producing abnormal neural connections in the developing visual system. A mutation in the gene-encoding tyrosinase (an enzyme necessary for melanin synthesis) causes an absence of pigment in the epithelium underlying the retina (Guillery, 1974). The resulting retinal disturbance causes certain optic fibers to be misrouted across the optic chiasm to the wrong side of the brain (Hubel \& Wiesel, 1971). These fibers form abnormal connections in the lateral geniculate nucleus, which in turn sends inappropriate fibers to the visual cortex. In normal cats, input from corresponding parts of the visual field of each eye is projected to the opposite side of the visual cortex, in a manner allowing binocular vision. But in the Siamese cat, the abnormal incoming fibers reorganize the cortex so that parts of it receive monocular input from only one eye. The result is a basically functional visual system in a cross-eyed cat.

In this example, the only direct effect of the tyrosinase mutation is to alter the course taken by certain nerve fibers. The rest of the nervous system is apparently normal. If the behavior of groups of neurons were directed by specific genes, one would expect the lateral geniculate nucleus and the visual cortex to reject foreign contacts and, blindly carrying out prespecified genetic instructions, fail to organize abnormal inputs. Instead, these structures respond flexibly to the arrival of unexpected axons. Following the sequence of intercellular interactions characteristic of normal development-not fixed information from "their own" genes-they create an orderly representation of highly abnormal inputs.

Innate behaviors are generally conceived of as stereotyped patterns of neural circuitry in the brain. The Siamese cat example illustrates that specific genes are not available to direct the development of the neural connections that produce normal vision, a very basic sensory ability. It consequently seems unreasonable to invoke countless 
specific genes to program the neural circuitry responsible for species-specific behaviors.

Neuronal death. In vertebrate and invertebrate nervous systems, the initial number of neurons generated greatly exceeds the number that ultimately survive (Hamburger \& Oppenheim, 1982; Truman, 1984). In vertebrate neural centers, where accurate counts of developing neurons are available, cell loss has been found to range from $40 \%$ to $75 \%$ (Cowan, 1979). The notion that some cells are defective or predestined to die has been proven false. All neurons in a given population send out normal axons that reach the target field. Here they evidently compete for synaptic sites, and those that form effective connections survive at the expense of the unsuccessful neurons. Experiments have shown that altering the size of the synaptic field proportionally alters the magnitude of neuron death. Thus, if target tissue is removed, more cells die (Cowan, 1973); if target tissue is added-by transplanting a limb, for example-more cells survive (Hollyday \& Hamburger, 1976). These experiments indicate that which and how many neurons survive is regulated epigenetically rather than genetically.

A phenomenon related to neuronal death is synapse elimination. In many cases, axons, upon reaching their target cells, produce an excessive number of connections. Later, many of the synaptic terminals are eliminated (Cowan, 1979; Harris, 1981). Changeux and Danchin (1976) have proposed that, during development, the pattern of spontaneous or evoked activity across connections specifies which synapses survive and which are eliminated, and thus specifies the final connectivity of the nervous system. Harris (1981) describes studies in which electrical activity across neuromuscular connections was blocked pharmacologically. In such cases, no synapse elimination occurred, indicating that activity does, indeed, play a role in regulating synapse number.

Behavior genetics. The key point in the above section is that specific genes do not control specific events in normal nervous system development. There are not one-toone correspondences between genes and neural structures, but rather many-to-many relationships, with each developmental stage guided by epigenetic information (Jacobson, 1978). It follows from this realization that, since specific genes do not specify neural circuitry, specific genes do not encode behaviors.

The prevalence of the concept that certain genes program or provide a blueprint for behaviors can in part be attributed to a misinterpretation of information generated by behavior geneticists. There now exists an extensive list of single-gene mutations that affect the behavior of organisms from Drosophila to humans (Ehrman \& Parsons, 1981). However, the significance of these "behavioral mutants" is sometimes misrepresented. Consider this series of statements made in a discussion of singlegene mutations in fruit flies (Ehrman \& Parsons, 1981, p. 166):
Many diverse behaviors are controlled by single genes situated at loci scattered throughout the fly's chromosomes.... Benzer and collaborators have studied ... three single-gene mutations altering the normal circadian (about 24 hours) rhythm exhibited by $D$. melanogaster ... Compelling evidence for the genetic control of this biological clock is presented by flies with the arrhythmic mutant, which eclose ad lib all day long; flies with the short-period mutant, which display a consistent 19- (not 24-) hour cycle; and flies with the long period mutant, which have a 28 -hour cycle.

These statements may suggest that the wild-type alleles of the identified mutations control the normal behavior in question. The authors certainly imply that because a mutation can alter a behavior, the altered behavior is necessarily genetically programmed. Both interpretations are false. The wild-type allele of a mutant gene is almost certainly not solely responsible for the normal adaptive behavioral trait and, in most cases, probably has nothing whatsoever to do with the construction of the adaptive behavior. Also, mutations that alter behavior are not in and of themselves "compelling evidence" that a given behavior is canalized, since the performance of learned behaviors can also be disrupted by mutations. It should be emphasized that all identified single-gene behavioral mutations are deleterious-they disrupt the development of the nervous system in complex and sometimes obscure ways. There is no unequivocal evidence that single genes can program adaptive, canalized behavior.

These points can be illustrated by the Siamese cat example described above. In this case, the single-gene mutation is apparently nonneural, but instead causes defective melanin synthesis. Clearly, the wild-type allele has nothing to do with the construction of a normal cat visual system. Stent (1981, p. 316) has expressed this point well:

The case of the Siamese cat reveals the conceptual poverty of the notion that genes specify the neural circuits that underlie behavior. All that the gene mutated in the Siamese cat can usefully be said to 'specify' is the amino acid sequence of an enzyme that takes part in melanin synthesis, presumably in the retinal epithelial cells ... the absence of the polypeptide chain it specifies sets off a cascade of dysfunctional, albeit specific, aberrations, which eventually lead to a specific reorganization of the feline brain. But despite these specific cerebral aberrations there is, in this paradigmatic case, no trace of genetic specification of neural circuitry.

Feature detectors and innate releasing mechanisms. If genes do not directly specify behaviors, then what form is the relationship between genes and behaviors likely to take? Below, I suggest that canalized behaviors may commonly be preceded evolutionarily by learned forms of the behaviors. An adaptive and persistent learned behavior may acquire a genetic base through the selection of mutations or the genetic assimilation of latent genetic variability which enhances the probability that the behavior will occur in an appropriate fashion. An important point 
to note here is that the cumulative genetic changes that "fix" learned behaviors may involve genes that have nothing to do with constructing the neural centers responsible for the learned behaviors. For example, one means by which learned behaviors may become genetically constrained is through the evolution of feature detectors. Feature detectors are identified sensory neurons that respond optimally to particular environmental features of adaptive importance to the animal. Frogs, for instance, have ganglion cells in their visual system that respond maximally to small, dark, erratically moving objects and that allow frogs to perceive flying insects (Maturana, Lettvin, McCulloch, \& Pitts, 1960). The presence of feature detectors may guide learned behaviors along species-specific channels, making them appear stereotyped and strongly canalized.

A comparison of feature detectors with the early ethological concept of innate releasing mechanisms may clarify the indirect relationship between genes and behaviors proposed in this paper. Lorenz and Tinbergen suggested that animals possess inherited perceptual mechanisms which recognize highly configural stimuli and which trigger specific behavioral responses (fixed action patterns). These perceptual mechanisms, called innate releasing mechanisms, were assumed to have a specific genetic basis and to be associated with discrete neural structures. Consequently, they generated the belief in behavioral genes which precisely programmed the development of neural structures responsible for complex behaviors. The concept of feature detectors, on the other hand, depends only on the belief that genes can directly or indirectly influence how perceptual systems function. Clearly, the cumulative genetic changes that create feature detectors need not involve hypothetical genes which program CNS circuitry. As the Siamese cat example illustrates, mutations in any part of the genome can set in motion a chain of epigenetic events that may eventually affect the nervous system in minor or major ways. Such mutated genes may be behaviorally important within the context of an adaptive learned behavior, but in and of themselves need have no intrinsic behavioral meaning. Thus, the relationship between genes and behaviors is likely to be highly obscure and, as stated in Alternative Hypotheses, too tenuous and indirect for us to view genes as programming behaviors.

\section{Plasticity in Adult Nervous Systems}

It appears to be a common belief among students of behavioral evolution that the nervous systems of most adult animals are static and immutable. Animals that have evolved the ability to learn are assumed to possess specialized, flexible neural centers that are remarkable exceptions to the hardwired nature of most animal brains. The purpose of this section is to point out that physiological and anatomical plasticity are basic and necessary features of all nervous systems. Studies show that neural connections are modified or replaced in response to injury, disease, malnutrition, altered environments, hormonal influences, use and disuse, and general wear and tear. The neural mechanisms underlying these ubiquitous nonlearning responses are in some cases similar to the identified neural changes underlying learning. Because nervous systems are generally dynamic and adaptable, the ability to alter behavior (i.e., learn) quantitatively, if not always qualitatively, is logically expected to be the rule and complete behavioral rigidity, the exception.

To support the statement that nervous systems are dynamic and adaptable, I will briefly describe two general mechanisms of neural plasticity. The first, synaptic renewal, is an example of anatomical plasticity; the second, synaptic potentiation, is an example of physiological plasticity.

Synaptic renewal. Synaptic renewal has been most extensively studied as a response to partial denervation of neurons or muscle fibers. If a lesion deprives neurons or muscles of some of their synapse, intact nerve fibers respond by sprouting new endings that form synapses to replace those lost as a consequence of the injury. This phenomenon occurs in both the peripheral and the central nervous systems of vertebrates and invertebrates (Cotman, Nieto-Sampedro, \& Harris, 1981; Cowan, 1979; Tsukahara, 1981). Damage to nerve endings may even cause synapse sprouting in areas of the nervous system well removed from the denervated area. Particularly interesting are cases in cats and primates, in which perturbation of peripheral neural structures causes synaptic growth and remodeling in the brain (Cotman \& NietoSampedro, 1982). A similar situation occurs in the cricket CNS, where removal of sensory structures causes the associated central neurons to acquire innervation from other cells (Palka \& Edwards, 1974). These examples indicate that considerable flexibility exists in the central neural connections of adult animals.

Significant for present purposes is the evidence presented by Cotman and Nieto-Sampedro $(1982,1984)$ that synapse loss and renewal occur in the adult nervous system in the absence of lesions. These authors argue that synapse renewal in response to injury is just an extension of the spontaneous synapse turnover that occurs continuously throughout the normal mature nervous system. Synapse turnover appears to be involved in the neural changes that occur in response to environmental factors. Many experiments have demonstrated that animals placed in "enriched" environments (large cages, other animals present) show increased neuroanatomical complexity-such as larger dendrites with more branches and spines-relative to animals placed in "impoverished" environments (small cages, no companions) (Greenough, 1984; Thompson, Berger, \& Madden, 1983).

Thompson et al. (1983) believe that the neural changes observed in these enriched/impoverished environment studies are similar to those that occur in the mammalian brain during learning. They point out that such changes are responses to peripheral stimulation and that the CSUCS information presented during conditioning likewise simply represents specific combinations of peripheral stimulation. In support of this idea, many studies have 
demonstrated increased neuroanatomical complexity in response to behavioral conditioning (Thompson et al., 1983). The increased complexity generally involves increases in dendrite branching and synapse numbers, phenomena undoubtedly coincident with synapse turnover. Thus, synaptic renewal, a basic process that occurs in all neural connections, may underlie at least some forms of learning.

Synaptic potentiation. Most nerve cells transmit information across chemical synapses. An action potential in one neuron sets off another action potential by releasing packets of transmitter that depolarize the membrane of a connected cell, causing a second action potential. Potentiation in this context refers to the fact that a high rate of activity across a chemical synapse can facilitate subsequent activity across this synapse. Many types of potentiation have been described, some of which are caused by an increased amount of $\mathrm{Ca}^{++}$present within the presynaptic ending. The amount of intracellular $\mathrm{Ca}^{++}$ an ion that briefly flows into cells during action potentials-directly determines how much transmitter is released, which in turn can determine how effectively the postsynaptic cell is excited.

For example, a series of rapid action potentials will saturate a presynaptic nerve terminal with $\mathrm{Ca}^{++}$, leaving an extra, residual amount of $\mathrm{Ca}^{++}$that enhances subsequent synaptic transmission for many minutes. Kandel (1981, p. 88) remarks:

Here then is the simplest case of memory! This neuron remembers that it has generated a train of impulses by increasing the intracellular concentration of $\mathrm{Ca}^{++}$in its terminals, and now ... produces more transmitter release than before.

The potentiation described by Kandel usually lasts for minutes, but can last for more than an hour. Another type of potentiation, called long-term potentiation, produces increases in synaptic efficacy that can persist for months. Many mechanisms have been proposed to explain how repetitive action potentials produce long-term potentiation (Swanson, Teyler, \& Thompson, 1982). In some cases, it may be produced presynaptically, for example by increased transmitter release (Skrede \& MaltheSorenssen, 1981); in other cases, changes to the postsynaptic membrane may enhance transmission (Lynch \& Baudry, 1984).

Clearly, the occurrence of potentiation at chemical synapses is potentially relevant to learning and memory. Neurobiologists have shown that this mechanism does indeed operate to produce learning in molluscs (Alkon, 1980, 1984; Hawkins, Abrams, Carew, \& Kandel, 1983; Kandel \& Schwartz, 1982), mammals (Lynch \& Baudry, 1984), and fish (Shashoua, 1982, 1985). However, it should be emphasized that potentiation is a general and widespread process, certainly not limited to animals capable of extensive learning. The process is an automatic consequence of the basic chemical and physiological way that nerve cells operate. Thus, the mechanism described above or similar mechanisms can be found wherever $\mathrm{Ca}^{++}$ modulated chemical transmission occurs-and that means in most parts of all known nervous systems.

\section{The Evolution of Canalized Behavior and Learning}

The alternative hypotheses presented at the start of this paper may now be considered in greater detail. I have attempted to demonstrate two main points: that behaviors are not encoded in genes, and that plasticity and learning are basic, primitive properties of nervous systems. It follows from these points that, first, there need be no differential genetic cost associated with canalized or learned behaviors. Rozin and Schull (in press) are concerned that we "have no way of measuring the genetic space occupied by a behavioral program," but speculate anyway about the genetic cost of various behaviors. Such concerns and speculations are fruitless, because behaviors simply don't occupy pieces of DNA. Second, there is no differential neural cost associated with canalized or learned behaviors. The belief that learning requires more neurons or different kinds of neurons than canalized behavior is denied by the realization that neural features allowing learning are intrinsic to most neurons.

The above information suggests that there is no a priori reason to assume that canalized behaviors phylogenetically predate learning, and indeed it is reasonable to suppose that in many instances the reverse is true. When this is the case, behavioral evolution may occur in a manner rather different from the way structural traits evolve. New structural traits emerge when random mutations or new genetic recombinations arise and become established in a population by natural selection. Behavior can evolve in a similar way. In this situation, which may be termed "passive" behavioral evolution, behavior changes depend on the natural selection of random mutations and sometimes lead, sometimes follow, the evolution of related morphological structures. Certainly, much essential behavioral evolution is expected to occur in this manner. Thus, basic behaviors, such as reproducing sexually and giving parental care, presumably evolve passively and are phylogenetically primitive.

However, behavioral change is not always constrained by genetic change, since the ability to learn allows individual animals to adaptively change their behavior in response to environmental challenges. Biologists recognize that behavior can consequently play an active evolutionary role, allowing animals to alter or select their habitat, and so change the selective pressures to which they are exposed (Mayr, 1963). The essence of this "active" view of behavior is that animals can make nonrandom (adaptive), nongenetic (not dependent on the occurrence and selection of fortuitous mutations in the style of passive behavioral evolution) responses to changes or opportunities in their environments. Animals are intrinsically active beings. If they can behave at all, they can perceive certain positive and negative aspects of their environment and adjust their behavior accordingly, at- 
tempting to acquire the first and avoid the latter. Consequently, learned behavioral solutions to environmental challenges are probably common evolutionary phenomena (Piaget, 1978).

Flexible learning potentially leading to active behavioral evolution may even occur in animals traditionally viewed as having limited and rigidly programmed learning abilities. Honeybees, for example, learn to avoid alfalfa after once experiencing a punch from the spring-loaded anther borne by these flowers. However, when bees are placed in the middle of acres of solid alfalfa-an evolutionarily novel experience-they soon deal adaptively with the flowers. Either they learn to recognize sprung from unsprung flowers and visit only the former or they learn to avoid unsprung anthers by taking nectar from a hole they chew through the side of the flower (Reinhardt, 1952, cited by Gould, 1982). Adaptive learned behaviors such as these may spread widely through a population and persist across many generations, with animals in each generation discovering the behavior by trial and error learning or imitation. Genetic changes that predispose animals to perform the behavior or enhance some component of it would presumably be adaptive and are expected to evolve. Genetic assimilation offers a potentially powerful mechanism for the rapid evolution of such genetic enhancement of learned behaviors.

Genetic assimilation of behavior. Waddington (1953, 1961) coined the term "genetic assimilation" to refer to a process by which morphological traits, acquired in response to a severe environmental perturbation, are converted by selection into inherited traits. The original expression of a new trait and its subsequent conversion to an inherited trait depend not on new mutations, but on latent genetic variation already present in the population. This variation is usually suppressed by the inherent tendency of a developing system to resist modification by genetic or environmental agents. A severely abnormal environment causes this tendency to break down, increasing the variability of development. Also, Waddington found that a specific environmental stress produced a specific morphological response; for instance, heat applied to Drosophila melanogaster pupae produced "crossveinless" flies (Waddington, 1953) and "bithorax" was caused by exposing eggs to ether (Waddington, 1956). This specificity, combined with the general disruption of development, allowed an abnormal condition to appear in a few animals which possessed the strongest genetic tendency for it. Subsequent selection of such animals increased the concentration of alleles causing the abnormal phenotype. Genetic assimilation occurred when these alleles became so numerous in certain individuals that the abnormal phenotype was produced genetically, with no further need for the original environmental stimulus. Because genetic assimilation depends on alleles already present in a population, Waddington suggested that the process could give rise to very rapid evolutionary changes.

If learned behaviors are, indeed, transformed to canalized behaviors by genetic assimilation, what exactly is as- similated? This depends on what sort of genetic variability is available in the population. But, as emphasized above, the process doesn't necessarily require the existence of genes directly associated with particular parts of central neural circuitry. Instead, components of learned behaviors may be enhanced by genetic changes that affect perceptual systems and create feature detectors. Hailman's study of pecking behavior in gull chicks offers an example of how this may occur. Hailman $(1967,1969)$ demonstrated that the pecking response of gull chicks, in which chicks peck at the tip of their parent's beak to cause the adult to regurgitate food, is not initially as stereotyped as previously reported (Tinbergen \& Perdeck, 1950). Instead, newly hatched chicks at first show a lack of coordination in pecking behavior and will peck at almost any sort of model. With practice, they learn to be much more accurate and selective in where they aim their pecks, responding only to models very similar to a gull's head. Despite the importance of learning, chicks do have inherent preferences to peck at certain simple things, for instance long vertical shapes and moving, rather than stationary, objects.

Tinbergen believed that the pecking response involved an innate releasing mechanism and fixed action pattern, in which chicks possessed inherited information on the configuration of a adult gull head and an innate, stereotyped response to this stimulus. However, the simplicity of the stimuli that initially elicit pecking suggests, instead, that gull chicks simply have feature detectors-neurons in the visual system highly responsive to moving vertical bars, for example. Feature detectors, and the similar experiences that confront chicks, cause the pecking response to become stereotyped and species typical and to consequently appear strongly canalized. The present model hypothesizes that pecking behavior emerged as an operantly conditioned learned response. Active chicks probably attract more parental attention than do quiescent chicks, and consequently undirected pecking could have caused food regurgitation to be enhanced and pecking to be reinforced. The feature detectors that adaptively canalize the behavior subsequently evolved through the assimilation of genes altering visual perception in gull chicks.

Hailman's work highlighted the possibility that many canalized behaviors may develop àlong species-typical channels guided by a few simple innate factors (feature detectors) and the similar conditions that confront conspecifics, rather than by precise, detailed genetic instructions. Gould (1982) has suggested that feature detectors are, indeed, the basis of classical innate releasing mechanisms and cites this realization as a cornerstone of modern ethology. That many canalized behaviors are under simple, rather than highly complex, specific genetic control is what one would expect if, as suggested here, many are preceded by learned forms of the same behavior. Other things being equal, natural selection will favor individuals possessing genes that directly or indirectly enhance an adaptive learned behavior. However, it is unlikely that a population will perchance possess sufficient and ap- 
propriate genetic variability to allow rapid genetic assimilation of an entire complex behavior. Consequently, many canalized behaviors may be viewed as learned behaviors equipped in random ways with a few or many genetic guideposts. I reemphasize that genes marshaled by natural selection to guide learned behaviors are not truly "behavioral genes." Simply, they are genes that affect the nervous system, perhaps very indirectly, and that achieve behavioral significance only within the context of a learned behavior.

Rozin and Schull (in press) have also suggested that learned behaviors may be replaced by canalized forms of the same behavior, perhaps by a process called "organic selection." This process, conceived of simultaneously by Baldwin (1896), Morgan (1896), and Osborn (1896), proposes that individual animals may adapt to new environments by nongenetic means. The acquired adaptations allow the population to persist until random mutation produces alleles which fix the new traits genetically. This process is certainly possible, but, because it depends upon the occurrence of suitable mutations, it would in theory operate less efficiently than genetic assimilation. In either process, the genome is viewed as tracking active behavioral adaptations via the natural selection of latent genetic variability or new mutations. Behaviors are constrained or refined genetically and, if ample time is available, canalized behaviors are forged from learned adaptations.

The hypothesis described above was developed in an attempt to provide an evolutionary theory of canalized and learned behavior consistent with contemporary knowledge of neurogenetics and neurophysiology. It may now be asked which theory, that based on traditional ideas or the present hypothesis, can best explain specific learning phenomena. Both theories suggest that environmental change is, in most cases, the key to understanding the evolution of learning versus canalized behavior: stable, predictable environments produce canalized behavior, and rapidly changing, unpredictable environments favor learning. According to the traditional theory, learning evolved as a complex, costly adaptation to cope with environmental change. In the alternative model, learned behaviors change too rapidly in response to changing environments to be converted by selection to canalized behaviors. Because both theories predict similar ends, though by quite different means, both can account for many of the same general phenomena.

Assessing the value and generality of the present hypothesis versus the traditional theory will require a rigorous consideration of many learning phenomena in terms of both theories, a treatment that must await another paper. However, I will conclude by suggesting that the present theory may better explain certain types of learning, such as bird song learning and imprinting, that are not well understood in terms of the traditional theory. These types of learning are problematic because they occur in some species, whereas other species perform similar tasks without learning. In the case of bird song learning, biologists have expended considerable theoretical effort in attempting to account for the evolution of this behavior (Kroodsma, 1982; Marler \& Mundinger, 1971; Nottebohm, 1972; Slater, 1983). But it is probably fair to say that no one has provided a truly convincing explanation for why some orders of birds learn songs, while many possess canalized repertories. Also puzzling are differences among species of song birds in the type and amount of learning required for the production of a normal species-specific song. Generally, birds reared in acoustic isolation fail to develop completely normal songs, confirming the importance of auditory experience in song bird vocal development. However, although in some species the song of isolates is highly abnormal (i.e., white crowned sparrows; Marler, 1970), in others the song is basically similar to that of wild birds, for example, cardinals (Dittus \& Lemon, 1969) and wood thrushes (Lanyon, 1979). Given some sort of auditory experience, there is also great variability in what can be learned. In some species, song learning is strongly canalized, such that only species-typical songs are learned, whereas in other species canalization is weak and a few or a great many heterospecific sounds can be copied (Kroodsma, 1982; Slater, 1983). Patterns of vocal ontogeny have been correlated to life history parameters in a few species (Catchpole, 1982; Slater, 1983). However, the suggested correlations are not widely applicable across species, and in most cases the adaptive value of song learning remains enigmatic. Roper (1983, p. 207) comments, "At present we have little idea why natural selection has left the song learning process so heavily constrained in some species and so flexible in others."

The present lack of generally applicable explanations may well reflect the fact that many differences between weakly and strongly canalized song development have no adaptive significance. If this is true, a traditional view of learning cannot satisfactorily account for the existence of song learning. If learning is a complex, biologically expensive adaptation, it presumably requires steady and compelling selective pressure to evolve; it would not be expected to pop up randomly and persist in situations where an alternative innate behavior could perform the task equally well. On the other hand, random differences in degrees of learning are readily understood in terms of the present theory. The genetic fixation of adaptive learning abilities depends not only on the direction and intensity of selection, but also on the availability of appropriate genetic variation in the population, and this is a random factor. Consequently, canalized behaviors evolve from learned behavior at different rates and from the assimilation of different genes, giving rise to random differences in degrees and kinds of learning at particular evolutionary times.

\section{REFERENCES}

Alcock, J. (1979). Animal behavior: An evolutionary approach. Sunderland, MA: Sinauer.

Alkon, D. L. (1980). Cellular analysis of a gastropod (Hermissenda crassicornis) model of associative learning. Biological Bulletin, 159 , 505-560. 
AlKon, D. L. (1984). Changes in membrane currents during learning. Journal of Experimental Biology, 112, 95-112.

BALDWIN, J. M. (1896). A new factor in evolution. American Naturalist, 30, 441-451.

BARASH, D. P. (1977). Sociobiology and behavior. New York: Elsevier. BATESON, P. O, G. (1971). Imprinting. In H. Moltz (Ed.), The ontogeny of vertebrate behavior (pp. 369-387). New York: Academic Press.

Bateson, P. P. G. (1984). Genes, evolution and learning. In P. Marler \& H. S. Terrace (Eds.), Dahlem workshop on the biology of learning (pp. 75-88). New York: Springer.

CATChPole, C. K. (1982). The evolution of bird sounds in relation to mating and spacing behavior. In D. E. Kroodsma \& E. H. Miller (Eds.), Acoustic communication in birds (Vol. 1, pp. 297-319). New York: Academic Press.

Changeux, J. P., Danchin, A. (1976). Selective stabilization of developing synapses as a mechanism for the specification of neuronal networks. Nature, 264, 705-712.

Cotman, C. W., \& Nieto-Sampedro, M. (1982). Brain function, synapse renewal, and plasticity. Annual Review of Psychology, 33, $371-401$.

Cotman, C. W., \& Nieto-Sampedro, M. (1984). Cell biology of synaptic plasticity. Science, 225, 1287-1294.

Cotman, C. W., Nieto-Sampedro, M., \& Harris, E. W. (1981). Synapse replacement in the nervous system of adult vertebrates. Physiological Review, 61, 684-784.

Couvillon, P. A., Bitterman, M. E. (1980). Some phenomena of associative learning in honeybees. Journal of Comparative \& Physiological Psychology, 94, 878-885.

CowAN, W. M. (1973). Neuronal death as a regulative mechanism in the control of cell number in the nervous system. In $M$. Rockstein (Ed.), Development and aging in the nervous system (pp. 19-41). New York: Academic Press.

Cowan, W. M. (1979). Selection and control in neurogenesis. In F. O. Schmitt \& F. C. Worden (Eds.), Neurosciences fourth study program (pp. 59-79). Cambridge: MIT Press.

DitTus, W. P. J., \& LEMON, R. E. (1969). Effects of song tutoring and acoustic isolation on the song repertoires of cardinals. Animal Behaviour, 17, 523-533.

Ehrman, L., Parsons, P. A. (1981). Behavior genetics and evolution. New York: McGraw-Hill.

GARCIA, J , \& KoElling, R. A. (1966). Relation of cue to consequence in avoidance learning. Psychonomic Science, 4, 123-124.

Goodman, C. S. (1979). Isogenic grasshoppers: Genetic variability and development of identified neurons. In X. Breakefield (Ed.), Neurogenetics: Genetic approaches to the nervous system (pp. 101-151). New York: Elsevier.

Gould, J. L. (1982). Ethology: The mechanics and evolution of behavior. New York: W. W. Norton.

Gould, J. L., MARLER, P. (1984). Ethology and the natural history of learning. In P. Marler \& H. S. Terrace (Eds.), Dahlem workshop on the biology of learning (pp. 47-74). New York: Springer.

GREENOUGH, W. T. (1984). Structural correlates of information storage in the mammalian brain: A review and hypothesis. Trends in Neuroscience, $73,229-233$

GUILLERY, R. W. (1974). Visual pathways in albinos. Scientific American, 230, 44-54.

Hallman, J. P. (1967). The ontogeny of an instinct. Behaviour Supplements, $15,1-159$.

Hailman, J. P. (1969). How an instinct is learned. Scientific American, 221, 98-108.

Haldane, J. B. S. (1959). Natural selection. In P. R. Bell (Ed.), Darwin's Biological Work (pp. 101-149). Cambridge: Cambridge University Press

Hall, J. C., GreEnspan, R. J. (1979). Genetic analysis of Drosophila neurobiology. Annual Review of Genetics, 13, 127-195.

HAMBURGER, V., \& OPPENHEIM, R. W. (1982). Naturally occurring neuronal death in vertebrates. Neuroscience Commentary, 1, 39-55.

HARRIS, W. A. (1981). Neural activity and development. Annual Review of Physiology, 43, 689-710.
Hawkins, R. D., Abrams, T. W., Carew, T. J., \& Kandel, E. R. (1983). A cellular mechanism of classical conditioning in Aplysia. Activity-dependent amplification of presynaptic facilitation. Science, 219, 400-405.

Hinde, R. A. (1970). Animal behaviour. New York: McGraw-Hill. HOLLYDAY, M., \& HAMBURGER, V. (1976). Reduction of the naturally occurring motor neuron loss by enlargement of the periphery. Journal of Comparative Neurology, 170, 311-320.

HubeL, D. H., \& WiEsel, T. N. (1971). Aberrant visual projections in the Siamese cat. Journal of Physiology, 218, 33-62.

JACOBSON, M. (1978). Developmental neurobiology. New York: Plenum Press.

Johnston, T. D. (1981). Contrasting approaches to a theory of learning. Behavioral \& Brain Sciences, 4, 125-173.

Johnston, T. D. (1982). Selective costs and benefits in the evolution of learning. Advances in the Study of Behavior, 12, 65-106.

KANDEL, E. R. (1981). Synaptic transmission II: Presynaptic factors controlling transmitter release. In E. R. Kandel \& J. H. Schwartz (Eds.), Principles of neural science. New York: Elsevier.

KANDEL, E. R., \& SCHWARTZ, J. H. (1982). Molecular biology of learning: Modulation of transmitter release. Science, 218, 433-443.

KING, A. P., \& West, M. J. (1977). Species identification in the North American cowbird: Appropriate responses to abnormal song. Science, $195,1002-1004$.

Kroodsma, D. E. (1982). Learning and the ontogeny of sound signals in birds. In D. E. Kroodsma \& E. H. Miller (Eds.), Acoustic communication in birds (pp. 1-23). New York: Academic Press.

LANYON, W. E. (1979). Development of song in the wood thrush (Hylocichla mustelina), with notes on a technique for hand-rearing passerine birds from the egg. American Museum Novitates, 2666, 1-27.

LeHrman, D. S. (1953). A critique of Konrad Lorenz's theory of instinctive behaviour. Quarterly Review of Biology, 28, 337-363

Levinthal, F., Macagno, E., \& Levinthal, C. (1975). Anatomy and development of identified cells in isogenic organisms. Cold Spring Harbor Symposia on Quantitative Biology, 40, 321-331.

LYNCH, G., \& BAUDRY, M. (1984). The biochemistry of memory: A new and specific hypothesis. Science, 224, 1057-1063.

Macagno, E. R., Lopresti, V., \& Levinthal, C. (1973). Structure and development of neuronal connections in isogenic organisms: Variation and similarities in the optic system of Daphnia magna. Proceedings of the National Academy of Sciences of the United States of America, 70, 57-61.

MARLER, P. A. (1970). A comparative approach to vocal learning: Song development in the white-crowned sparrow. Journal of Comparative \& Physiological Psychology, 71, 1-25.

MARler, P., \& Mundinger, P. (1971). Vocal learning in birds. In $\mathrm{H}$. Moltz (Ed.), The ontogeny of vertebrate behavior ( $\mathrm{pp} .389-450$ ). New York: Academic Press.

Maturana, H. R., Lettvin, J. Y., McCulloch, W. S., \& Pitts, W. H. (1960). Anatomy and physiology of vision in the frog (Rana pipiens). Journal of General Physiology, 43, 129-175.

MAYr, E. (1963). Animal species and evolution. Cambridge, MA: Harvard University Press.

MAYr, E. (1974). Behavior programs and evolutionary strategies. American Scientist, 62, 650-659.

MCGUIRE, T. R., \& HiRSCH. J. (1977). Behavior-genetic analysis of Phormia regina: Conditioning, reliable individual differences, and selection. Proceedings of the National Academy of Sciences of the United States of America, 74, 5193-5197.

MoRGAN, C. L. (1896). Habit and instinct. London: Arnold.

Noттевонм, F. (1972). The origins of vocal learning. American Naturalist, 106, 116-140.

OsBoRN, H. F. (1896). A mode of evolution requiring neither natural selection nor the inheritance of acquired characters. Transactions of the New York Academy of Sciences, 15, 141-142.

Palka, J., Edwards, J. S. (1974). The cerci and abdominal giant fibers of the house cricket, Acheta domesticus. II. Regeneration and effects of chronic deprivation. Proceedings of the Royal Society of London B, 185, 105-121. 
Partridge, L. (1983). Genetics and behaviour. In T. R. Halliday \& P. J. B. Slater (Eds.), Genes, development and behavior (pp. 11-51). New York: Freeman.

PIAGET, J. (1978). Behavior and evolution. New York: Random House.

Plotkin, H. C., \& Odling-Smee, F. J. (1979). Learning, change and evolution: An enquiry into the teleonomy of learning. Advances in the Study of Behavior, 10, 1-41.

ROPER, T. J. (1983). Learning as a biological phenomenon. In T. R. Halliday \& P. J. B. Slater (Eds.), Genes, development and behavior (pp. 178-212). New York Freeman.

Rozis, P. (1976). The evolution of intelligence and access to the cognitive unconscious. Progress in Psychobiology \& Physiological Psychology, 6, 245-280.

RoziN, P., Schull, 3. (in press). The adaptive-evolutionary point of view in experimental psychology: A critical analysis of "constraints." In R. C. Atkinson, R. J. Herrnstein, G. Lindzey, \& R. D. Luce (Eds.), Handbook of experimental psychology. New York: Wiley.

SAHLEY, C., RUdY, J. W., \& GELPERIN, A. (1981). An analysis of associative learning in a terrestrial mollusc. Journal of Comparative Physiology, 144, 1-8.

ShashouA, V. E. (1982). Molecular and cell biological aspects of learning: Towards a theory of memory. Advances in Cellular Neurobiology, 3, 97-141.

ShashouA, V. E. (1985). The role of extracellular proteins in learning and memory. American Scientist, 73, 364-370.

SHEPHERD, G. M. (1983). Neurobiology. Oxford: Oxford University Press.

Skrede, K. K. \& Malthe-SorensSen, D. (1981). Increased resting and evoked release of transmitter following repetitive electrical tetanization in hippocampus: A biochemical correlate to long-lasting synaptic potentiation. Brain Research, 208, 436-441.

Slater, P. J. B. (1983). Bird song learning: Theme and variations. In A. H. Brush \& G. A. Clark (Eds.), Perspectives in ornithology (pp. 475-511). Cambridge: Cambridge University Press.

StadDon, J. E. R. (1983). Adaptive behavior and leaming. Cambridge: Cambridge University Press.
STENT, G. (1981). Strength and weakness of the genetic approach to the development of the nervous system. In W. M. Cowan (Ed.), Studies in developmental neurobiology (pp. 288-321). Oxford: Oxford University Press.

Swanson, L. W., Teyler, T. J., \& Thompson, R. F. (1982). Hippocampal long-term potentiation: Mechanisms and implications for memory. Neurosciences Research Program Bulletin, 20, 617-764.

Thompson, R. F., Berger, T. W., \& Madden, J., IV (1983). Cellular processes of learning and memory in the mammalian CNS. $A n$ nual Review of Neuroscience, 6, 447-491.

Tinbergen, N., \& Perdeck, A. C. (1950). On the stimulus situations releasing the begging response in the newly hatched herring gull (Lanus argentatus Pont.). Behaviour, 3, 1-39.

Truman, J. W. (1984). Ceil death in invertebrate nervous systerns. Annual Review of Neuroscience, 7, 171-188.

TsUkahara, N. (1981). Synaptic plasticity in the mammalian central nervous system. Annual Review of Neuroscience, 4, 351-379.

WADDINGTON, C. H. (1953). Genetic assimilation of an acquired character. Evolution, 7, 118-126.

WADDINGTON, C. H. (1956). Genetic assimilation of the bithorax phenotype. Evolution, 10, 1-13.

WADDINGTON, C. H. (1961). Genetic assimilation. Advances in Genetics, 10, 257-293.

Ward, S., Thomson, N., White, J. C., \& Brenner, S. (1975). Electron microscopical reconstruction of the anterior anatomy of the nematode Caeanorhabditis elegans. Journal of Comparative Neurology, 160, 313-338.

Williams, G. C. (1966). Adaptation and natural selection. Princeton, NJ: Princeton University Press.

(Manuscript received June 2, 1986; revision accepted for publication September 3, 1986. ) 